\title{
The role of the hippocampus in retaining relational information across short delays: The importance of memory load
}

\author{
Annette Jeneson, ${ }^{1}$ Kristin N. Mauldin, ${ }^{2}$ Ramona O. Hopkins, ${ }^{3,4}$ and Larry R. Squire ${ }^{1,2,5,6,7}$ \\ ${ }^{1}$ Department of Psychology, University of California, San Diego, California 92093, USA; ${ }^{2}$ Department of Psychiatry, University of \\ California, San Diego, California 92093, USA; ${ }^{3}$ Department of Psychology and Neuroscience Center, Brigham Young University, Provo, \\ Utah 84602, USA; ${ }^{4}$ Department of Medicine, Pulmonary and Critical Care Division, Intermountain Medical Center, Murray, Utah \\ 84143, USA; ${ }^{5}$ Veterans Affairs Medical Center 116A, San Diego, California 92161, USA; ${ }^{6}$ Department of Neurosciences, University of \\ California, San Diego, California 92093, USA
}

\begin{abstract}
Patients with hippocampal damage are sometimes impaired at remembering information across delays as short as a few seconds. How are these impairments to be understood? One possibility is that retention of some kinds of information is critically dependent on the hippocampus, regardless of the retention interval and regardless of whether the task depends on working memory or long-term memory. Alternatively, retention may be dependent on the hippocampus only when the task involves a memory load large enough to exceed working memory capacity. To explore these possibilities, we assessed the performance of patients with hippocampal lesions on two tasks requiring retention of the same objectin-scene information across a brief delay. The tasks placed different demands on memory. In one task, which used a continuous recognition format, participants needed to try to hold up to nine scenes in mind, even when no scene intervened between the study scene and the corresponding test scene. Patients were impaired in this condition. In a second task, using a conventional study-test format, participants needed to hold in mind only one scene at a time for either 3 or $14 \mathrm{sec}$. With this procedure, patients performed as well as controls after a 3-sec delay but were impaired after a 14-sec delay. We suggest that retention of object-in-scene information is dependent on the hippocampus only when working memory is insufficient to support performance (because memory load is high or the retention interval is long). In these circumstances performance depends, at least in part, on long-term memory.
\end{abstract}

[Supplemental material is available for this article.]

Working memory refers to the ability to hold a limited amount of information actively in mind, usually across a brief time interval (Baddeley 2003). Early studies of memory-impaired patients with medial temporal lobe (MTL) damage, including the noted patient H.M., found this ability to be spared despite their severe impairment in long-term memory (Drachmann and Arbit 1966; Baddeley and Warrington 1970; Milner 1972; Cave and Squire 1992; Squire 2009). The principle that emerged from these investigations was that working memory (sometimes termed shortterm memory) is independent of the hippocampus and adjacent MTL structures. It is therefore notable that a number of recent studies have reported that patients with MTL damage can be impaired at remembering information across quite brief time intervals (Hannula et al. 2006; Nichols et al. 2006; Olson et al. 2006a,b; Hartley et al. 2007; Kan et al. 2007; Piekema et al. 2007; Bird and Burgess 2008; Ezzyat and Olson 2008; Finke et al. 2008). In addition, functional magnetic resonance imaging (fMRI) studies have reported MTL activation during short-delay recognition memory tasks (Ranganath and D'Esposito 2001; Schon et al. 2004; Ranganath et al. 2005; Nichols et al. 2006; Piekema et al. 2006, 2010; Axmacher et al. 2007; Hannula and Ranganath 2008; Toepper et al. 2010). These observations have

${ }^{7}$ Corresponding author.

E-mail Isquire@ucsd.edu; fax (858) 552-7457.

Article is online at http://www.learnmem.org/cgi/doi/10.1101/lm.2010711. raised the possibility that working memory may sometimes depend on the MTL.

While the emerging fMRI literature does implicate a role for the MTL in some tasks involving brief retention intervals, it is less clear whether the findings implicate a role for the MTL in working memory. For example, it has been noted that MTL activity may reflect incidental encoding of or rehearsal of novel items in support of long-term memory rather than activity needed for active maintenance of information in working memory (e.g., Ryan and Cohen 2004; Zarahn et al. 2005; Olsen et al. 2009). If the fMRI findings can be understood without requiring a role of the MTL in working memory, how then should we understand the striking observations of impaired performance after MTL damage in tasks with delays as short as a few seconds?

In one study that explored recognition memory, patients with hippocampal damage performed well at remembering scenes, but were impaired at remembering information about the locations of objects in a scene. The impairment in objectlocation information was evident even at the briefest delay when no stimuli intervened between study and test (i.e., memory was impaired even at a lag of one item in a continuous recognition test format) (Hannula et al. 2006). One possibility is that maintenance of information about objects in a scene is critically dependent on the MTL, regardless of whether performance must span short or long delays and regardless of whether performance depends on working memory or long-term memory (Hannula 
et al. 2006). If so, the nature of the task (e.g., object-in-scene memory vs. sceneonly memory) might be more fundamental for understanding hippocampal function than the classical distinction between working memory and long-term memory.

It is also possible that impaired memory performance across brief time intervals sometimes occurs because working memory capacity has been exceeded. Two important factors that influence working memory capacity are the amount of information that can be held in mind and how amenable this information is to active rehearsal. These considerations imply that the capacity of working memory can sometimes be exceeded, even at short retention intervals. For example, when presented with 10 word pairs and asked for immediate recall, memory-impaired patients recall many fewer word pairs than controls (zero or one pair vs. five or six pairs). Perhaps (as considered by Hannula et al. 2006), an impairment in object-in-scene memory at a lag of one item could mean that the capacity of working memory was exceeded. Indeed, even at a lag of one item, participants in the earlier study still needed to try to hold in mind a number of previous scenes (up to nine), because the decision to identify each item as old or new depended on as many as the previous nine items. In addition, there was a delay of 14 sec between the initial presentation of a study scene and the assessment of memory for object location.

We conducted two experiments. In the first experiment, we used the same procedure as was used previously (Hannula et al. 2006). In the second experiment, we used a conventional test paradigm consisting of successive study-test trials that involved either a brief (3-sec) or a relatively long (14-sec) retention interval. For this test procedure, participants were required to hold in mind only one scene at a time. If maintenance of object-in-scene information is critically dependent on the hippocampus, hippocampal damage should impair performance at the 3-sec retention interval, even in a conventional test paradigm.

Five memory-impaired patients participated (four men) (Table 1), all of whom have bilateral lesions thought to be limited to the hippocampus (CA fields, dentate gyrus, and subicular complex). Detailed descriptions of these patients are provided in

Table 1. Characteristics of memory-impaired patients

\begin{tabular}{lccccccccc}
\hline & & & & & & \multicolumn{5}{c}{ WMS-R } \\
\cline { 6 - 9 } Patient & Gender & $\begin{array}{c}\text { Age } \\
\text { (years) }\end{array}$ & $\begin{array}{c}\text { Education } \\
\text { (years) }\end{array}$ & $\begin{array}{c}\text { WAIS-III } \\
\text { IQ }\end{array}$ & Attention & Verbal & Visual & General & Delay \\
\hline K.E. & $\mathrm{M}$ & 67 & 13.5 & 108 & 114 & 64 & 84 & 72 & 55 \\
L.J. & $\mathrm{F}$ & 71 & 12 & 101 & 105 & 83 & 60 & 69 & $<50$ \\
G.W. & $\mathrm{M}$ & 49 & 12 & 108 & 105 & 67 & 86 & 70 & $<50$ \\
J.R.W. & $\mathrm{M}$ & 45 & 12 & 90 & 87 & 65 & 95 & 70 & $<50$ \\
R.S. & $\mathrm{M}$ & 52 & 12 & 99 & 99 & 85 & 81 & 82 & $<50$ \\
\hline
\end{tabular}

WAIS-III is the Wechsler Adult Intelligence Scale-III and the WMS-R is the Wechsler Memory Scale-Revised. The WMS-R does not provide numerical scores for individuals who score $<50$. IQ scores for J.R.W. and R.S. are from the WAIS-R.
Jeneson et al. (2010a). Estimates of medial temporal lobe damage were based on quantitative analysis of magnetic resonance (MR) images (Bayley et al. 2005; Gold and Squire 2005). Nine coronal magnetic resonance images from each patient, together with detailed descriptions of the lesions, are presented as supplemental material (Supplemental Fig. 1, available online). Nine controls also participated (eight males; mean age, 58.4 years; mean education, 14.0 years).

The procedure for Experiment 1 was based on an earlier study of memory for objects in scenes (Hannula et al. 2006, Experiment 1 ), as described in Figure 1. The stimuli consisted of 48 unique scenes $(800 \times 600$ pixels) created using Punch! Home Design software (kindly provided by Dr. Hannula). Two versions of each scene were available (for a total of 96 stimuli): the original scene and a manipulated version of the scene in which the spatial relations among scene elements were changed (e.g., an urn was moved from the left side to the right side of the room) (Fig. 1). Participants completed two blocks of trials in a continuous recognition format. Each block consisted of 24 study trials (the original scenes) interleaved with 24 test trials (12 scenes that were repeated versions of the originally studied scenes and 12 that were manipulated versions of the scenes). There were two different pseudorandom orders of scenes for each 
Table 2. Performance on tests of scene memory and location memory in Experiment 1

\begin{tabular}{|c|c|c|c|c|c|}
\hline & Lag 1 hits & Lag 5 hits & Lag 9 hits & Overall CR & $\begin{array}{l}\text { Overall percent } \\
\text { correct }\end{array}$ \\
\hline \multicolumn{6}{|l|}{ Scene memory } \\
\hline Controls & $99.3(1.0)$ & $99.7(0.5)$ & $99.3(1.0)$ & $99.8(0.2)$ & $99.6(0.2)$ \\
\hline Patients $(n=5)$ & $97.5(1.5)$ & $95.0(5.0)$ & $96.3(3.8)$ & $80.4(7.4)^{\mathrm{a}}$ & $88.3(3.5)^{\mathrm{a}}$ \\
\hline \multicolumn{6}{|l|}{ Location memory } \\
\hline Controls & $100(0.0)$ & $83.3(5.5)$ & $81.9(4.7)$ & $87.4(3.6)$ & $87.9(2.4)$ \\
\hline \multirow[t]{2}{*}{ Patients $(n=5)$} & $80.0(10.2)^{a}$ & $54.2(5.7)^{\mathrm{a}}$ & $50.8(15.5)^{\mathrm{a}}$ & $72.2(11.1)^{a}$ & $66.8(3.5)^{\mathrm{a}}$ \\
\hline & Lag 1 CR & Lag 5 CR & Lag 9 CR & & \\
\hline \multicolumn{6}{|l|}{ Location memory } \\
\hline Controls & $83.3(4.2)$ & $86.6(4.9)$ & $91.7(3.6)$ & $87.2(3.6)$ & $87.9(2.4)$ \\
\hline Patients $(n=5)$ & $72.5(15.0)$ & 77.5 (11.5) & $65.0(9.8)^{\mathrm{a}}$ & $71.6(11.1)^{\mathrm{a}}$ & $66.8(3.5)^{\mathrm{a}}$ \\
\hline
\end{tabular}

Mean percent hits (and SEM) at each lag, overall percent correct rejections (CR) across lags, and CRs at each lag for location memory. CRs cannot be calculated for scene memory because novel items are presented only once and have no "lag." Overall percent correct is mean percent correct across lags (overall hit rate + overall CR rate/2).

${ }^{\text {a }}$ Significantly poorer than controls, $P<0.05$.

block of 48 trials. For each participant, (1) an equal number of repeated and manipulated probe trials were presented at each lag, (2) the critical item was equally often at the left or right in the scene, and (3) at each lag, the orienting question was equally likely to be associated with a "yes" (or "no") response.

The patients were modestly impaired at answering the first yes/no question about whether a scene had been presented earlier in the block (Table 2). Overall, the patients scored $88.3 \pm 3.5 \%$ correct at classifying the scene as old or new, and the controls scored $99.6 \pm 0.2 \%$ correct $\left(t_{(4.0)}=3.26, P=0.03\right.$, unequal variance $t$-test). The result was the same when the data were analyzed using $d^{\prime}$ scores ( 2.8 vs. 4.1 for patients and controls, respectively; $t_{(4.0)}=6.13, P=0.004$, unequal variance $t$-test).

The patients were also impaired at answering the second yes/ no question about whether any items in the scene had changed location (Table 2; Fig. 2A). ${ }^{8}$ An analysis of variance (ANOVA) for lag $(1,5$, or 9$)$ and group (patients with hippocampal lesions vs. controls) revealed an effect of group $\left(F_{(1,12)}=26.2, P<0.001\right)$ as well as an effect of lag $\left(F_{(2,24)}=6.9, P=0.004\right)$ but no lag-group interaction $\left(F_{(2,24)}=1.9, P=0.17\right)$. The hippocampal patients were impaired at all three lags $\left(t_{(12)}>2.8, P \mathrm{~s}<0.02\right)$. The result was the same when the data were analyzed using $d^{\prime}$ scores (patients, 1.60, 0.93, and 0.49; controls, 2.52, 2.10, and 2.20, for lags of 1, 5, and 9, respectively; all $\left.t \mathrm{~s}_{(12)}>2.6, P \mathrm{~s}<0.03\right)$.

Experiment 2 was based on Experiment 1, but used a more conventional procedure to test memory for scenes (Fig. 3). The stimuli consisted of the same 48 scenes as in Experiment 1 plus 48 new scenes created by us using the same software as in Experiment 1. Ninety-six manipulated versions of each scene were also used, 48 from Experiment 1 and 48 new scenes created by us. Participants completed eight test blocks in a single session (12 study-test trials/block). The study-test delay was the same (3 or $14 \mathrm{sec}$ ) for all 12 trials in a block, and the delay alternated from block to block. The scene presented after the delay was the same as the studied scene on half of the trials and was altered on half of the trials. Two different versions of the test were available so that, across participants, each scene was equally likely

${ }^{8}$ The score for the question about whether any items had changed location was calculated as follows: (hit rate + correct rejection rate) $/ 2$, where hit rate refers to the percent of test scenes that were correctly identified as altered, and the correct rejection rate refers to the percent of scenes that were correctly identified as unaltered. Trials were scored only when the "yes" response to the first question was correct and when the response to the orienting question was also correct (orienting question: patients with hippocampal lesions, 99.2\% correct; controls, $98.4 \%$ correct). to be repeated or manipulated. In addition, across participants, each scene was equally likely to be tested after a 3- and 14-sec delay. The interval between Experiment 1 and Experiment 2 was at least $6 \mathrm{wk}$ (mean $=22.6 \mathrm{wk})$. Experiment 1 always preceded Experiment 2.

The patients performed well at the 3-sec delay when deciding whether any items had changed location, but they were impaired at answering the same question after the 14-sec delay (Fig. 2B) (3-sec delay: $t_{(4.1)}=1.3, P=0.28$, unequal variance $t$-test; $14 \mathrm{sec}$ delay: $t_{(5.0)}=3.9, P=0.01$, unequal variance $t$-test). As in Experiment 1, trials were scored only when the participant gave a correct response to the orienting question (both hippocampal patients and controls scored $97.1 \%$ correct).

The fact that the group means differed at all at the brief (3-sec) delay was due to one patient who scored $85.0 \%$ correct. The mean score of the other four patients was $96.3 \%$ (controls $=$ $97.4 \%$ correct). The results were the same when the data were analyzed using $d^{\prime}$ scores (at $3 \mathrm{sec}$, patients 3.3, controls 3.7, $t_{(12)}=1.5, P=0.15$; at $14 \mathrm{sec}$, patients 2.1 , controls $3.4, t_{(12)}=$ 4.4, $P<0.001)$.
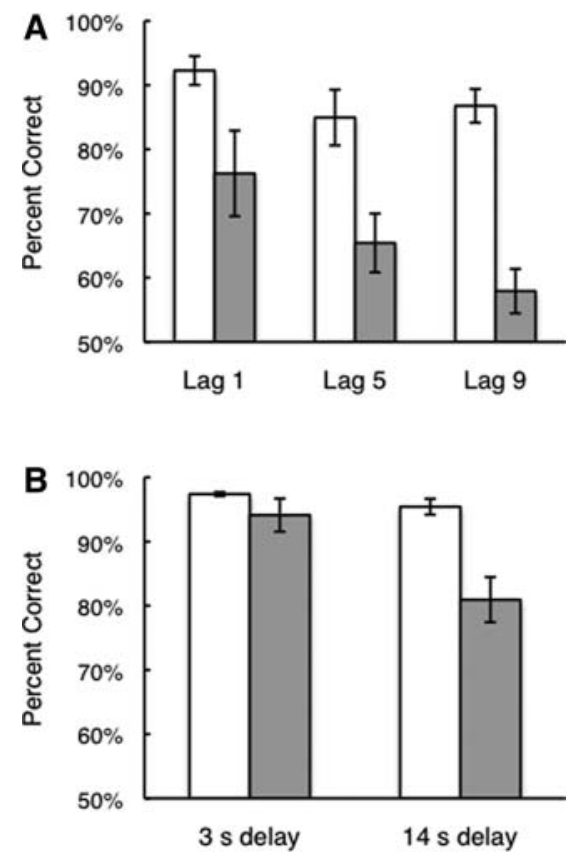

Figure 2. (A) Experiment 1. Performance of memory-impaired patients with hippocampal lesions (gray bars, $n=5$ ) and matched controls (white bars, $n=9$ ) on a test of memory for spatial relations among items in a scene. The patients were impaired at all lags. Nevertheless, they did score above chance at a lag of 1 and at a lag of $5\left(t_{(4)}>3.3\right.$, Ps $<$ $0.02)$, and they scored marginally above chance at a lag of $9\left(t_{(4)}=\right.$ 2.30, $P=0.08$ ). Error bars indicate SEM. (B) Experiment 2. Performance of memory-impaired patients with hippocampal lesions (gray bars, $n=$ 5 ) and matched controls (white bars, $n=9$ ). The patients performed well when memory was tested after a short (3-sec) delay, but they were impaired when memory was tested after a longer (14-sec) delay. Despite the marked impairment, patient performance was above chance at the 14-sec delay $\left(t_{(4)}=8.8, P<0.001\right)$. Error bars indicate SEM. 


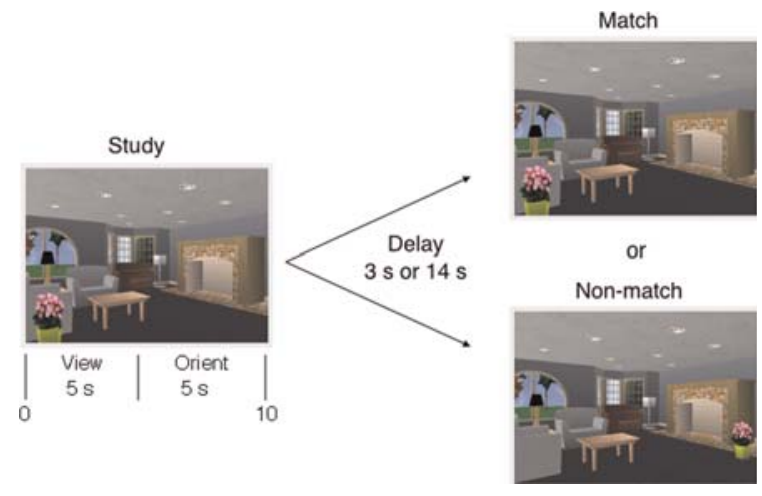

Figure 3. Experiment 2. A sample study-test trial. Participants first studied the scene to the left for $5 \mathrm{sec}$ and then were asked an orienting question ("Is the plant on the table?" [No]). After viewing the scene for a total of $10 \mathrm{sec}$, a delay of 3 or $14 \mathrm{sec}$ intervened before either a matching or nonmatching scene was presented together with a memory question ("Have any items changed location?"). Only this question was asked. In the nonmatching scene illustrated here, the plant has moved from left to right.

Experiment 1 replicated the results of an earlier study that used the same continuous recognition procedure (Hannula et al. 2006). The impairment observed with this procedure raised the possibility that the hippocampus is sometimes critical for maintaining object-in-scene information, regardless of whether the task depends on working memory or long-term memory (Hannula et al. 2006; see Olson et al. 2006b; Finke et al. 2008 for similar suggestions about other kinds of tasks). An alternative possibility, also considered by the authors of the earlier study (Hannula et al. 2006), is that impaired memory for object-in-scene information across brief time intervals sometimes occurs because performance under those conditions depends on long-term memory (also see Ryan and Cohen 2004 for a similar suggestion).

We reasoned that the continuous recognition procedure used in the earlier study (Hannula et al. 2006) and in Experiment 1 might indeed depend on long-term memory because of the requirement that, even for memory decisions made after a lag of 1 item, participants nonetheless needed to try to be holding in mind as many as nine earlier items. That is, participants were not only holding in mind information about the immediately preceding item, they also needed to try to hold in mind information about the previous nine items. To test this idea, we constructed a test (Experiment 2) in which the same object-in-scene information needed to be retained over the same brief delay. However, in this case only a single item was presented. Although patients were impaired at a brief delay in Experiment 1, they performed well in Experiment 2. The key difference in the two conditions was that in Experiment 1 participants needed to try to carry a memory load involving the previous nine items, but in Experiment 2 they needed to remember only a single item.

Note that object-in-scene memory (in Experiment 1) was impaired, but that scene memory itself (in Experiment 1) was less impaired. It seems reasonable to suppose that the burden on working memory of maintaining object-in-scene information was greater than the burden of maintaining scene-only information. In the case of object-in-scene memory, it was necessary to remember specific details about each scene, whereas scene-only memory required only that participants remember the general appearance of each scene.

It is notable that visual working memory is quite limited in capacity (Luck and Vogel 1997; Cowan 2001; Wheeler and
Treisman 2002; Alvarez and Cavanagh 2004). Typically, in healthy young adults, only three to four simple visual objects can be maintained (Cowan 2001; Fukuda et al. 2010). Accordingly, in Experiment 1, when as many as nine items involving complex scenes needed to be held in mind for successful performance, it is reasonable to suppose that the task exceeded working memory capacity and that performance depended, at least in part, on long-term memory.

In several studies, patients with bilateral medial temporal lobe damage have been found to be impaired at remembering visual information over brief delays where no stimuli intervene between study and test. In some cases, impairments were observed after a delay as short as 1 or $2 \mathrm{sec}$. Specifically, impairments have been noted in memory tasks for three object-location associations after 1 and $8 \mathrm{sec}$ (Olson et al. 2006b), for topographical scene information after $2 \mathrm{sec}$ (Hartley et al. 2007), and for a single face after $1 \mathrm{sec}$ (Ezzyat and Olson 2008, in a forced-choice task). The question of interest is whether the impairments found after short delays reflect impaired working memory or, if working memory capacity has been exceeded, an impairment in long-term memory.

This issue has been addressed in the case of retention intervals of $8 \mathrm{sec}$ or longer (Shrager et al. 2008) as well as in the case of a retention interval as short as $1 \mathrm{sec}$ (Jeneson et al. 2010b). Shrager et al. (2008) found concordance between the performance of patients with medial temporal lobe damage and the effect on control performance of distraction between study and test. It was assumed that distraction would be disruptive when performance depended on maintaining information in working memory. The finding was that the patients were intact on tasks in which distraction disrupted control performance, suggesting that the patients were successful when they could maintain information in working memory. In contrast, the patients were impaired on tasks in which distraction minimally affected control performance, suggesting that the patients failed when performance depended significantly on long-term memory.

To explore memory for object-location associations across delays as short as $1 \mathrm{sec}$, Jeneson et al. (2010b) drew on a method suggested by the classic study of digit span in patient H.M. (Drachman and Arbit 1966). The task required participants to maintain up to seven object-location associations across a 1-sec delay. Patients with medial temporal lobe damage performed similarly to controls when only a small number of object-location associations needed to be remembered, but they exhibited an abrupt decline in performance when as many as three to four object locations needed to be remembered. The marked discontinuity in patient performance as they moved from smaller to larger set sizes occurred at about the same set size that first produced errors in controls. Presumably, controls began making errors at this point because the material now exceeded their working memory capacity. These findings suggested that maintenance of relational information in working memory is intact in patients with medial temporal lobe damage. The patients were impaired only when the task exceeded working memory capacity such that longterm memory now benefitted performance. This method may have a useful application to other reports of impaired performance after short retention intervals.

The results of the current study are consistent with the findings of Shrager et al. (2008) and Jeneson et al. (2010b). The challenge has been to understand the impairment associated with medial temporal lobe lesions that can be observed in some tasks after brief delays. It has been suggested that the ability to form new associations is an important factor, regardless of the retention interval (Ranganath and Blumenfeld 2005; Hannula et al. 2006; Olson et al. 2006b; Finke et al. 2008). Memory load is also an important factor. A question then is whether the medial temporal 
lobe is required in some tasks regardless of how much material needs to be maintained (i.e., memory load), or whether the medial temporal lobe is required only when the memory load is large enough (or the retention interval long enough) such that long-term memory now benefits performance. We reasoned that if retention of object-in-scene information is critically dependent on the medial temporal lobe, then hippocampal damage should impair performance even when the memory load is minimal (and the retention interval is short). We assessed the performance of patients with hippocampal lesions on two tests requiring retention of the same information across a brief delay. The patients were intact on the test where the memory load was minimal and the retention interval was short, but they were impaired on the test where the memory load was greater (Experiment 1) or when the retention interval was long (Experiment 2). We suggest that retention of object-in-scene information is dependent on the hippocampus only when working memory is not sufficient to support performance, and performance depends, at least in part, on long-term memory.

\section{Acknowledgments}

This research was supported by the Medical Research of the Department of Veterans Affairs, National Institute of Mental Health (NIMH) Grant MH24600, and the Metropolitan Life Foundation. We thank Dr. Hannula for providing stimulus materials, and Jennifer Frascino, Christine Smith, and John Wixted for assistance and advice.

\section{References}

Alvarez GA, Cavanagh P. 2004. The capacity of visual short-term memory is set both by visual information load and by number of objects. Psychol Sci 15: $106-111$.

Axmacher N, Mormann F, Fernández G, Cohen MX, Elger CE, Fell J. 2007. Sustained neural activity patterns during working memory in the human medial temporal lobe. J Neurosci 27: 7807-7816.

Baddeley A. 2003. Working memory: Looking back and looking forward. Nat Rev Neurosci 4: 829-839.

Baddeley AD, Warrington EK. 1970. Amnesia and the distinction between long- and short-term memory. J Verb Learn Verb Be 9: 176-189.

Bayley PG, Gold JJ, Hopkins RO, Squire LR. 2005. The neuronatomy of remote memory. Neuron 46: 799-810.

Bird CM, Burgess N. 2008. The hippocampus and memory: Insights from spatial processing. Nat Rev Neurosci 9: 182-194.

Cave C, Squire LR. 1992. Intact verbal and non-verbal short-term memory following damage to the human hippocampus. Hippocampus 2: $151-163$.

Cowan N. 2001. The magical number 4 in short-term memory: A reconsideration of mental storage capacity. Behav Brain Sci 24: $87-114$.

Drachman DA, Arbit J. 1966. Memory and the hippocampal complex. II. Is memory a multiple process? Arch Neurol 15: 52-61.

Ezzyat Y, Olson IR. 2008. The medial temporal lobe and visual working memory: Comparisons across tasks, delays, and visual similarity. Cogn Affect Behav Neurosci 8: 32-40.

Finke C, Braun M, Ostendorf F, Lehmann T-N, Hoffmann K-T, Kopp U, Ploner CJ. 2008. The human hippocampal formation mediates short-term memory of colour-location associations. Neuropsychologia 46: $614-623$.

Fukuda K, Awh E, Vogel EK. 2010. Discrete capacity limits in visual working memory. Curr Opin Neurobiol 20: 177-182.

Gold JJ, Squire LR. 2005. Quantifying medial temporal lobe damage in memory-impaired patients. Hippocampus 15: 79-85.

Hannula DE, Ranganath C. 2008. Medial temporal lobe activity predicts successful relational memory binding. J Neurosci 28: 116-124.
Hannula DE, Tranel D, Cohen NJ. 2006. The long and the short of it: Relational memory impairments in amnesia, even at short lags. J Neurosci 26: 8352-8359.

Hartley T, Bird CM, Chan D, Cipolotti L, Husain M, Vargha-Khadem F, Burgess N. 2007. The hippocampus is required for short-term topographical memory in humans. Hippocampus 17: 34-48.

Jeneson A, Kirwan CB, Squire LR. 2010a. Recognition memory and the hippocampus: A test of the hippocampal contribution to recollection and familiarity. Learn Mem 17: 63-70.

Jeneson A, Mauldin KN, Squire LR. 2010b. Intact working memory for relational information after medial temporal lobe damage. J Neurosci 30: $13624-13629$.

Kan IP, Giovanello KS, Schnyer DM, Makris N, Verfaellie M. 2007. Role of the medial temporal lobes in relational memory: Neuropsychological evidence from a cued recognition paradigm. Neuropsychologia 45: 2589-2597.

Luck SJ, Vogel EK. 1997. The capacity of visual working memory for features and conjunctions. Nature 390: 279-281.

Milner B. 1972. Disorders of learning and memory after temporal lobe lesions in man. Clin Neur 19: 421-466.

Nichols EA, Kao YC, Verfaellie M, Gabrieli JD. 2006. Working memory and long-term memory for faces: Evidence from fMRI and global amnesia for involvement of the medial temporal lobes. Hippocampus 16: 604-616.

Olsen RK, Nichols EA, Chen J, Hunt JG, Glover GH, Gabrieli JDE, Wagner A. 2009. Performance-related sustained and anticipatory activity in human medial temporal lobe during delayed match-to-sample. J Neurosci 29: 11880-11890.

Olson IR, Moore KS, Stark M, Chatterjee A. 2006a. Visual working memory is impaired when the medial temporal lobe is damaged. J Cogn Neurosci 18: $1087-1097$.

Olson IR, Page K, Moore KS, Chatterjee A, Verfaellie M. 2006b. Working memory for conjunctions relies on the medial temporal lobe. J Neurosci 26: $4596-4601$.

Piekema C, Kessels RP, Mars RB, Petersson KM, Férnandez G. 2006. The right hippocampus participates in short-term memory maintenance of object-location associations. Neuroimage 33: 374-382.

Piekema C, Fernandez G, Postma A, Hendriks MP, Wester AJ, Kessels RP. 2007. Spatial and non-spatial contextual working memory in patients with diencephalic or hippocampal dysfunction. Brain Res 1172: 103-109.

Piekema C, Kessels RPC, Rijpkema M, Fernández G. 2010. The hippocampus supports encoding of between-domain associations within working memory. Learn Mem 16: 231-234.

Ranganath C, Blumenfeld RS. 2005. Doubts about double dissociations between short- and long-term memory. Trends Cogn Sci 9: 374-380.

Ranganath C, D'Esposito M. 2001. Medial temporal lobe activity associated with active maintenance of novel information. Neuron 31: $865-873$.

Ranganath C, Cohen MX, Brozinsky CJ. 2005. Working memory contributes to long-term memory formation: Neural and behavioral evidence. J Cogn Neurosci 17: 994-1010.

Ryan JD, Cohen NJ. 2004. The nature of change detection and online representations of scenes. J Exp Psychol Hum 5: 998-1015.

Schon K, Hasselmo ME, Lopresti ML, Tricarico MD, Stern CE. 2004. Persistence of parahippocampal representation in the absence of stimulus input enhances long-term encoding: A functional magnetic resonance imaging study of subsequent memory after a delayed match-to-sample task. J Neurosci 24: 11088-11097.

Shrager Y, Levy DA, Hopkins RO, Squire LR. 2008. Working memory and the organization of brain systems. J Neurosci 28: 4818-4822.

Squire LR. 2009. The legacy of patient H.M. for neuroscience. Neuron 61: 6-9.

Toepper M, Markowitsch HJ, Gebhardt H, Beblo T, Thomas C, Gallhofer B, Driessen M, Sammer G. 2010. Hippocampal involvement in working memory encoding of changing locations: An fMRI study. Brain Res 1354: $91-99$.

Wheeler ME, Treisman AM. 2002. Binding in short-term visual memory. J Exp Psychol Gen 131: 48-64.

Zarahn E, Rakitin B, Abela D, Flynn J, Stern Y. 2005. Positive evidence against human hippocampal involvement in working memory maintenance of familiar stimuli. Cereb Cortex 15: 303-316.

Received September 10, 2010; accepted in revised form February 23, 2011. 


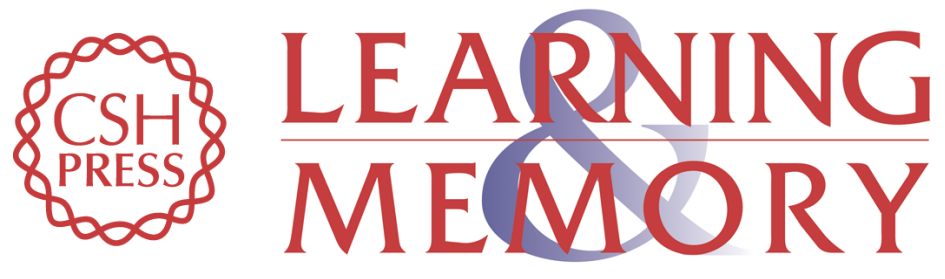

\section{The role of the hippocampus in retaining relational information across short delays: The importance of memory load}

Annette Jeneson, Kristin N. Mauldin, Ramona O. Hopkins, et al.

Learn. Mem. 2011, 18:

Access the most recent version at doi:10.1101/lm.2010711

Supplemental http://learnmem.cshlp.org/content/suppl/2011/04/18/18.5.301.DC1
Material

References This article cites 38 articles, 9 of which can be accessed free at:

http://learnmem.cshlp.org/content/18/5/301.full.html\#ref-list-1

License

Email Alerting Receive free email alerts when new articles cite this article - sign up in the box at the Service top right corner of the article or click here. 